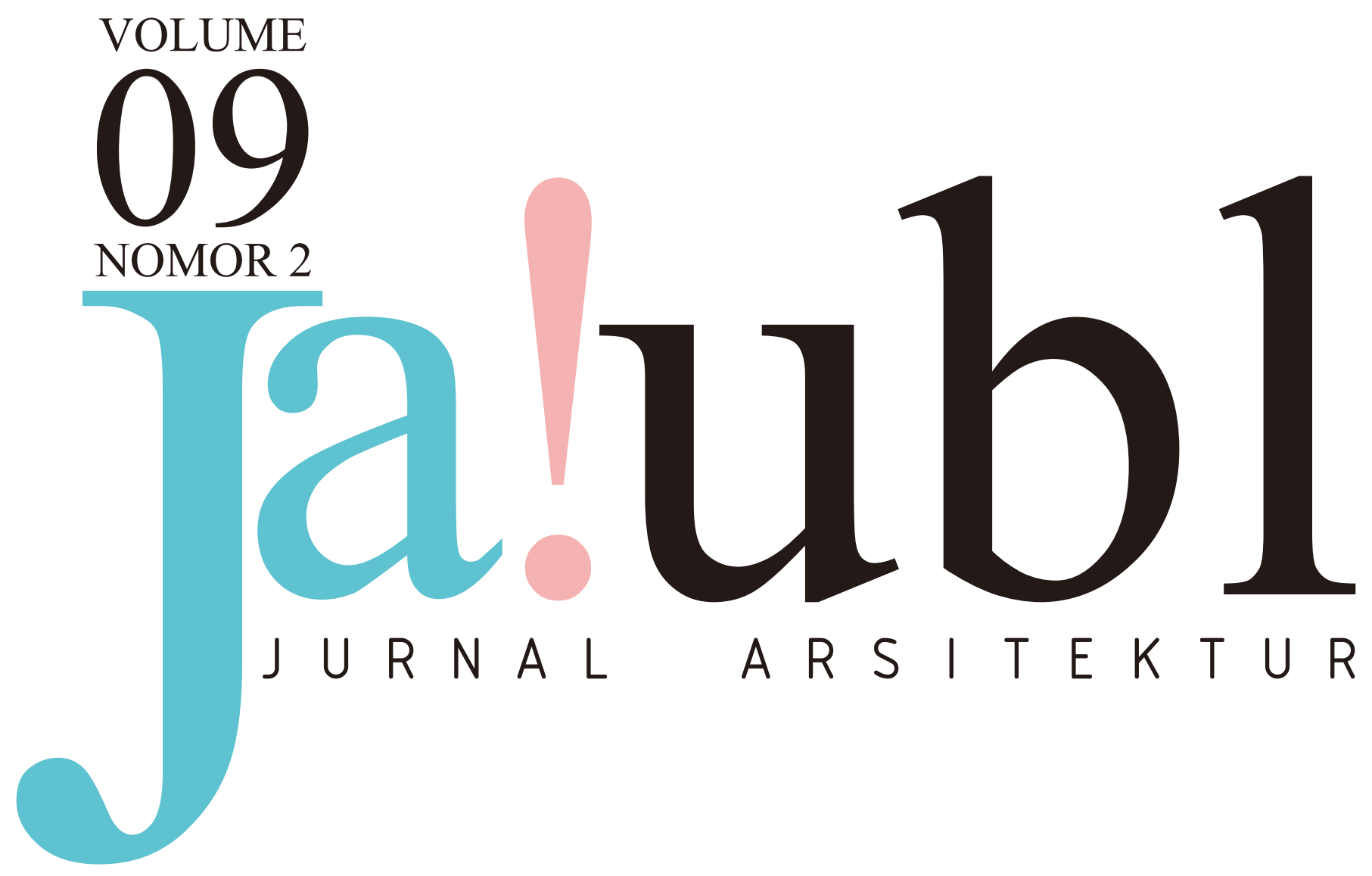


JA!UBL - Jurnal Arsitektur

Terbit dua kali setahun pada bulan Januari dan Juli. Diterbitkan oleh Program Studi Arsitektur Fakultas Teknik Universitas Bandar Lampung. JA!UBL merupakan media pendokumentasian, sharing, dan publikasi karya ilmiah yang berisi karya-karya riset ilmiah mengenai bidang ilmu perancangan arsitektur dan bidang ilmu lain yang sangat erat kaitannya seperti perencanaan kota dan daerah, desain interior, perancangan lansekap, dan sebagainya.

ISSN: 2087-2739

\section{PELINDUNG}

Dr. Ir.H.M.Yusuf Barusman, M.B.A. (Universitas Bandar Lampung)

\section{PENASEHAT}

Dr. Ir. Hery Riyanto, M.T. (Universitas Bandar Lampung)

PENANGGUNG JAWAB

Ir. Tjetjeng Sofjan S., M.M., M.T. (Universitas Bandar Lampung)

\section{PIMPINAN REDAKSI}

Dr.Eng. Haris Murwadi, S.T., M.T.

\section{REDAKSI PELAKSANA}

Shofia Islamia Ishar, S.T., M.T.

Dadang Hartabela, S.T., M.T.

Ai Siti Munawaroh, S.Pd., M.I.L.

Indyah Kumoro Wardani, S.T., IAI

\section{DEWAN REDAKSI}

Prof. Dr. Julaihi Wahid (Universitas Sains Malaysia)

Prof. Dr. Ir. H. Slamet Tri Sutomo, M.S (Universitas Hasanuddin)

Prof. Ir. Totok Rusmanto, M.Eng. (Universitas Diponegoro)

Prof. Dr. Ing. Ir Gagoek Hardiman. (Universitas Diponegoro)

Dr.Eng. Fritz Akhmad Nuzir, S.T., M.A.(L.A.) (Universitas Bandar Lampung)

David Hutama, ST., M.Eng (Universitas Pelita Harapan)

\section{MITRA BESTARI}

Dr. Ir. Budi Prayitno, M.Eng. (Universitas Gajah Mada)

Dr. Eng. Ir. Ahmad Sarwadi, M.Eng (Universitas Gajah Mada)

Prof. Dr. T. Yoyok Wahyu Subroto, M.Eng. Ph. D. (Universitas Gajah Mada)

Dr.Eng. Fritz Akhmad Nuzir, S.T., M.A. (L.A.) (Universitas Bandar Lampung)

Prof. Ir. Liliany Sigit Arifin, M.Sc., Ph. D (Universitas Petra)

Dr. Budi Faisal (Institut Teknologi Bandung)

Dr.Eng. Agus Hariyadi, S.T., M.Sc. (Universitas Gajah Mada)

\section{TIM GRAFIS DESAIN}

Satrio Agung Perwira

B. Chrysvania Artemisia

\section{ALAMAT REDAKSI}

Program Studi Arsitektur Fakultas Teknik Universitas Bandar Lampung

Jalan Zainal Abidin Pagar Alam Nomor. 26 Labuhanratu, Bandarlampung, 35142

Telp. $\quad:$ :0721-773847

E-mail : : editor.j@ubl.ac.id

Homepage : ubl.ac.id 


\section{Daftar Isi Artikel}

01-06 Analisis Penerapan Art Deco pada Rumah di Bandung Periode Perang Dunia I-II Studi Kasus: Tiga Villa dan Perumahan Dosen UPI FADILASARI, Dewi

07-12 Tipologi Bentuk Atap pada Arsitektur Jawa ROOSANDRIANTINI, Josephine; SANTOSO, Angelina Novemita; AMBARWATI, Catherina Novita

13-18 Identifikasi Respon Pengunjung mengenai Keberadaan Desa Wisata Taman Purbakala Pugungraharjo Lampung HARTABELA, Dadang; MASITO, Yuni

19-26 Fenomena Terbentuknya Ruang Spatio-Temporal di Kawasan Stadion Pahoman Bandarlampung WIBAWA, M. Shubhi Yuda

27-32 Identifikasi Area Berpotensi Macet di Kawasan Pendidikan Jl. Z.A. Pagar Alam Bandarlampung PERWIRA, Satrio Agung; MURWADI, Haris; MUNAWAROH, Ai Siti; ISHAR, Shofia Islamia

33-40 Manfaat Ruang Terbuka dan Hubungannya dengan Kegiatan Interaksi Sosial Studi Kasus: Perumahan Nusa Tamalanrea Indah Makassar NURHIJRAH; WIKANTARIA, Ria 


\title{
Identifikasi Respon Pengunjung mengenai Keberadaan Desa Wisata Taman Purbakala Pugungraharjo Lampung
}

\author{
Dadang Hartabela ${ }^{1 *}$, Yuni Masito ${ }^{2}$ \\ 1,2 Program Studi Arsitektur, Fakultas Teknik, Universitas Bandar Lampung \\ *Penulis Korespondensi: dadang.hartabela@ubl.ac.id; Telp. +62 857-9887-9629
}

\begin{abstract}
Abstrak:
Indonesia memiliki banyak tempat tujuan wisata mulai dari wisata alam, bahari, sejarah, kuliner, maupun yang lainnya. Salah satunya adalah Desa Wisata Taman Purbakala Pugungraharjo. Lokasinya berada di kabupaten Lampung Timur yang berlokasi di Kecamatan Sekampung Udik, Provinsi Lampung. Menurunnya jumlah pengunjung Desa Wisata Taman Purbakala Pugungraharjo dalam berapa tahun terakhir menjadi permasalahan yang menarik untuk diteliti. Sehingga perlu diketahui bagaimana Respon pengunjung terhadap kenyamanan, kepuasan dan pengetahuannya agar dapat diminati kembali oleh para pengunjung. Penelitian ini menggunakan metode kuantitatif dengan teknik pengumpulan data menggunakan observasi, dokumentasi, wawancara dan kuesioner. Teknik analisis data menggunakan metode kuantitatif- deskriptif dengan bantuan software berbasis olah data excel kemudian dideskripsikan ke dalam kalimat- kalimat penjelas. Faktor- faktor yang dianalisis terbagi menjadi tiga, yaitu tingkat kenyamanan, tingkat kepuasan, dan tingkat pengetahuan pengunjung. Tingkat kenyamanan terdiri dari kenyamanan visual, aroma, suara, dan penghawaan. Sedangkan tingkat kepuasan terdiri dari kondisi infrastruktur, transportasi, keterjangkauan lokasi, fasilitas Desa Wisata, dan nilai manfaatnya bagi masyarakat. Untuk tingkat pengetahuan dilihat dari pengetahuan pengunjung dan sumber informasi yang didapatkannya. Hasil penelitian ini menunjukkan bahwa Desa Wisata Taman Purbakala Pugungraharjo ini masih cukup diminati oleh wisatawan, namun masih perlu banyak peningkatan dan perbaikan. Terutama dalam hal infrastrktur atau sarana prasarana yang disediakan. Untuk penelitian selanjutnya, perlu diketahui lebih dalam mengenai harapan masyarakat setempat dan pengunjung untuk pengembangan desa wisata ini. Sehingga hasil temuan dapat menjadi bahan pertimbangan pemerintah dan masyarakat dalam mengembangkan Desa Wisata Taman Purbakala Pugungraharjo sebagai desa wisata favorit sepanjang masa dan ramah terhadap lingkungan.
\end{abstract}

Kata Kunci: Desa wisata; taman purbakala; Pugungraharjo; pengembangan wisata; respon pengunjung

\section{Latar Belakang}

Desa Wisata merupakan suatu bentuk integrasi antara atraksi, akomodasi dan fasilitas pendukung yang disajikan dalam suatu struktur kehidupan masyarakat yang menyatu dengan tata cara dan tradisi yang berlaku. Indonesia memiliki banyak sekali tempat tujuan wisata mulai dari wisata alam, bahari, sejarah, kuliner, maupun yang lainnya. Salah satunya di Provinsi Lampung, ada desa wisata yang cukup menarik tepatnya berada di kabupaten Lampung Timur yang berlokasi di Kecamatan Sekampung Udik yaitu Desa Wisata Taman Purbakala Pugungraharjo. Sejarah lahirnya Desa Wisata Taman Purbakala Pugungraharjo, Lampung Timur ini bermula dari temuan benda-benda purbakala pada tahun 1954. Pada situs arkeologi Taman Purbakala Pugungraharjo ini terdapat komplek peninggalan dari masa megalitik seperti arca, pundan berundak, batu mayat, altar batu, menhir, batu berlubang, serta dolmen peninggalan periode klasik berupa prasasti, dan keramik dari Dinasti Han, Dinasti Sun, dan Dinasti Ming. Maka dari itu Pemerintah Bandarlampung dan masyarakat sekitar harus melestarikan dan mengembangkan Desa Wisata di Taman Purbakala Pugungraharjo ini agar tetap ada hingga masa depan karena banyaknya ilmu yang didapat pada tempat pariwisata ini dan tidak mudah tersingkirkan karena mulai banyaknya tempat- tempat pariwisata baru yang tren di masa kini yang hanya memamerkan keindahan namun tidak ada manfaat untuk pungunjung itu sendiri. Oleh karena itu Desa Wisata Taman Purbakala ini harus dikembangkan dan menjadikan sebagai desa wisata yang bukan hanya terlihat lebih menarik, indah, nyaman, saja namun dapat bermanfaat sehingga pengunjung yang datang tidak hanya bersenang- senang saja tetapi juga memiliki pengetahuan tentang peninggalan- peninggalan pada jaman purba.

Menurunnya jumlah pengunjung Desa Wisata Taman Purbakala Pugungraharjo dalam berapa tahun terakhir menjadi permasalahan yang menarik untuk diteliti. Sehingga perlu diketahui bagaimana respon pengunjung terhadap kenyamanan, kepuasan dan pengetahuannya saat datang ke Desa Wisata Taman Purbakala agar mengetahui cara untuk mengembangkan dan mengoptimalkan kembali desa wisata ini seperti awal pembukaan 
Taman Purbakala Pugungraharjo untuk dapat diminati kembali oleh para pengunjung.

Menurut Mangunwijaya (1997), faktor kenyamanan fisik terdiri dari kenyamanan ruang, kenyamanan visual, kenyamanan termal (penghawaan), dan kenyamanan audio/suara (kebisingan). Sedangkan Hakim (2003) menyatakan bahwa faktor kenyamanan terdiri dari sirkulasi, iklim, kebisingan, aroma/bau-bauan, bentuk, keamanan, kebersihan, dan keindahan. Di sisi lain, Zeithaml dan Bitner (2000) mendefinisikan kepuasan sebagai respon atau Respon konsumen mengenai pemenuhan kebutuhan. Faktor-faktor yang mempengaruhinya yaitu: kualitas pelayanan atau jasa, kualitas produk, harga, faktor situasi, dan faktor pribadi konsumen. Menurut Notoatmodjo (2007), pengetahuan adalah hasil dari seorang yang melakukan penginderaan terhadap obyek tertentu. Penginderaan terjadi melalui panca indera manusia, yakni indera penglihatan, pendengaran, penciuman, rasa dan raba. Dengan demikian faktor kenyamanan, kepuasan, dan pengetahuan memiliki keterkaitan yang cukup besar, sehingga dapat menjadi indikator dalam menilai keberhasilan suatu obyek wisata berdasarkan respon atau Respon pengunjung.

\section{Metode}

Penelitian ini menggunakan metode kuantitatif (Creswell, 2008). Lokasi penelitian berada di Provinsi Lampung tepatnya di Desa Wisata Taman Purbakala di Desa Pugungraharjo, Kecamatan Jabung Kabupaten Lampung Timur.

\subsection{Metode Pengumpulan Data}

Metode pengumpulan data yang digunakan adalah survei (turun lapangan), observasi, wawacara, kuesioner, dan dokumentasi dalam bentuk foto. Populasi dalam penelitian ini adalah seluruh pengunjung Desa Wisata Taman Purbakala Pugungraharjo, sedangkan sampel responden berjumlah 91 orang. Metode pemilihan sampel menggunakan simple random sampling yaitu secara acak berdasarkan kondisi dan situasi pada saat penelitian lapangan berlangsung. Waktu pengumpulan data dilakukan dari pukul 10.00 WIB sampai dengan pukul 16.00 WIB dengan durasi 4 - 6 jam sehari. Pengumpulan data dilakukan selama 3 hari yaitu pada tanggal 19 Oktober 2017, 16 Desember 2017, dan 17 Desember 2017. Secara rinci dapat dilihat pada tabel 1.

Tabel 1. Waktu Pengumpulan Data dan Jumlah Responden

\begin{tabular}{cccc}
\hline Hari / Tanggal & Waktu & Durasi & $\begin{array}{c}\text { Jumlah } \\
\text { Responden }\end{array}$ \\
\hline Kamis ,19 Oktober 2017 & $10.00 \mathrm{~s} / \mathrm{d} 16.00$ & 6 jam & 4 orang \\
Sabtu, 16 Desember 2017 & $10.00 \mathrm{~s} / \mathrm{d} \mathrm{16.30}$ & 6 jam 30 menit & 56 orang \\
Minggu, 17 Desember 2017 & $11.00 \mathrm{~s} / \mathrm{d} \mathrm{15.00}$ & 4 jam & 31 orang \\
\hline
\end{tabular}

\subsection{Metode Analisis Data}

Teknik analisis data menggunakan metode kuantitatif (Creswell, 2008) dengan bantuan software berbasis olah data excel kemudian dideskripsikan ke dalam kalimat- kalimat penjelas. Faktor-faktor yang dianalisis terbagi menjadi tiga, yaitu tingkat kenyamanan, tingkat kepuasan, dan tingkat pengetahuan pengunjung.

\section{Hasil dan Pembahasan}

\subsection{Tingkat Kenyamanan Pengunjung}

Untuk mengetahui respon pengunjung terhadap kenyamanan yang dirasakannya, maka indera manusia menjadi alat yang cukup efisien dalam memberikan penilaian. Tingkat kenyamanan pengunjung tersebut dapat dilihat dari empat faktor, yaitu: visual (kebersihan dan keindahan), aroma (bau-bauan), suara (kebisingan), dan penghawaan (termal). Keempat faktor itu akan mewakili tingkat kenyamanan pengunjung Desa Wisata Taman Purbakala Pugungraharjo.

\subsubsection{Visual}

Secara visual dapat dilihat dari faktor keindahan dan kebersihan. Berdasarkan faktor keindahan, sebagian besar pengunjung (46,2\%) mengganggap bahwa Desa Wisata Taman Purbakala Pugungraharjo ini menarik secara visual, $33 \%$ merasa sangat tertarik dan 18,7\% cukup tertarik. Sebaliknya, hanya sedikit pengunjung yang menganggap tidak menarik yaitu 2,2\%. Berdasarkan faktor kebersihan, seluruh responden menjawab positif yaitu $53,8 \%$ bersih, $34,1 \%$ cukup bersih, dan $12,1 \%$ sangat bersih. Tidak ada responden yang menganggap tidak bersih. 


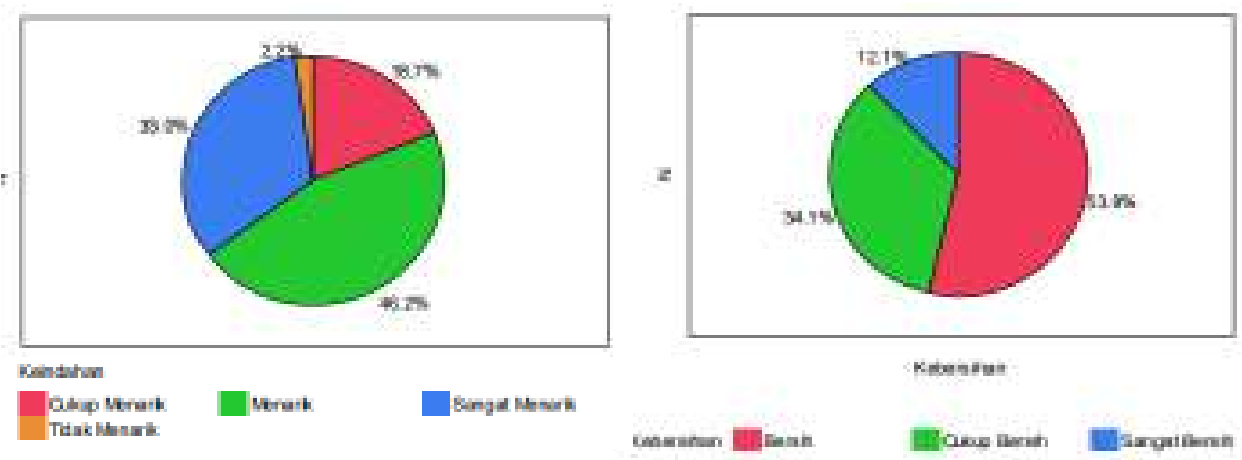

Gambar 1. Tingkat Kenyamanan Visual Pengunjung

\subsubsection{Aroma/Bau-bauan}

Sebagian besar responden (67\%) beranggapan bahwa desa wisata ini tidak bau. Sedangkan sisanya 33\% menganggap ada bau yang tidak sedap. Setelah ditelusuri lebih lanjut, aroma tidak sedap atau bau tersebut berada di dekat kolam megalitik, hal ini karena terdapat kandang ayam milik warga yang letaknya berdekatan.

\subsubsection{Suara/ Kebisingan}

Sebagian besar responden $(65,9 \%)$ mengganggap bahwa desa wisata ini tidak bising. Sedangkan $34,1 \%$ sisanya menganggap ada suara bising atau mengganggu aktivitas berwisata.

\subsubsection{Penghawaan}

Berdasarkan hasil penelitian, mayoritas responden (40,7\%) merasa kondisi pengahawaan di desa wisata ini biasa saja atau normal (tidak dingin dan tidak panas). Sedangkan 36,3\% responden merasa sejuk atau cukup dingin. Sisanya $12,1 \%$ merasa panas, $7,7 \%$ merasa dingin sekali, dan 3,3\% merasa panas sekali.

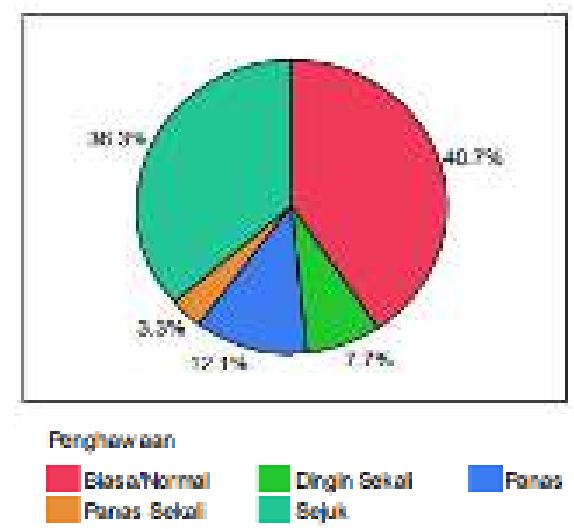

Gambar 2. Tingkat Kenyamanan Penghawaan Pengunjung

\subsection{Tingkat Kepuasan Pengunjung}

Untuk mengetahui respon pengunjung terhadap kepuasan yang dirasakannya, maka kondisi fisik yang dilihat dan dirasakan pengunjung menjadi faktor yang dapat dinilai. Tingkat kepuasan terdiri dari kondisi infrastruktur, transportasi, keterjangkauan lokasi, fasilitas desa wisata, dan nilai manfaatnya bagi masyarakat. Kelima faktor itu akan mewakili tingkat kepuasan pengunjung Desa Wisata Taman Purbakala Pugungraharjo.

\subsubsection{Kondisi Infrastruktur}

Kondisi ini dilihat dari kondisi jalan menuju Desa Wisata Taman Purbakala Pugungraharjo dan kondisi area parkir. Berdasarkan hasil penelitian, sebagian besar responden beranggapan bahwa kondisi jalan menuju desa wisata tersebut dianggap cukup baik (39,6\%). Sedangkan yang menjawab baik sebesar 36,3\% dan sangat baik $4,4 \%$. Sebaliknya yang menganggap bahwa kondisi jalan menuju desa wisata ini tidak baik sebesar $14,3 \%$ dan sangat tidak baik sebesar 5,5\%. Berdasarkan kondisi area parkir, sebagian besar responden beranggapan bahwa kondisi fisik area parkir di lokasi desa wisata tersebut baik (51,6\%). Sisanya 36,3\% menjawab cukup baik, 6,6\% sangat baik. Hanya sebagian kecil 5,5\% yang merasa bahwa kondisi fisik area parkir desa wisata ini tidak baik. Dengan demikian masih perlu adanya perbaikan pada infrastruktur jalan menuju desa wisata ini. 

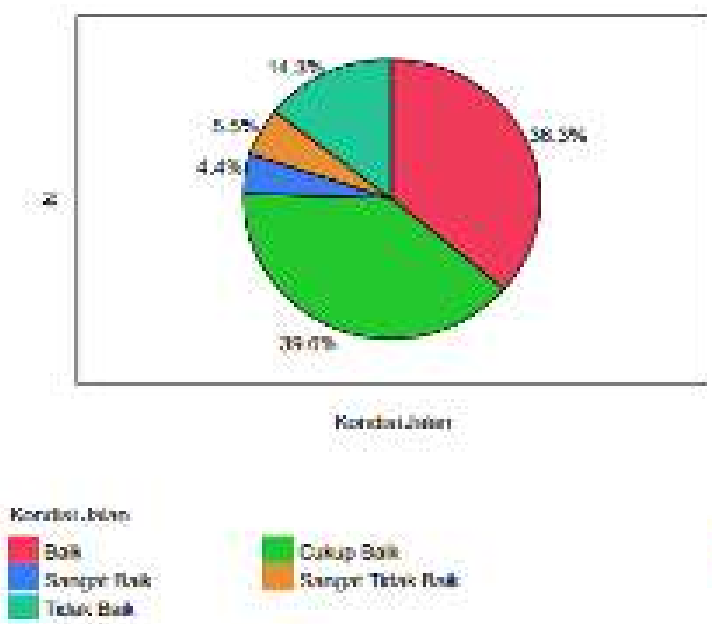

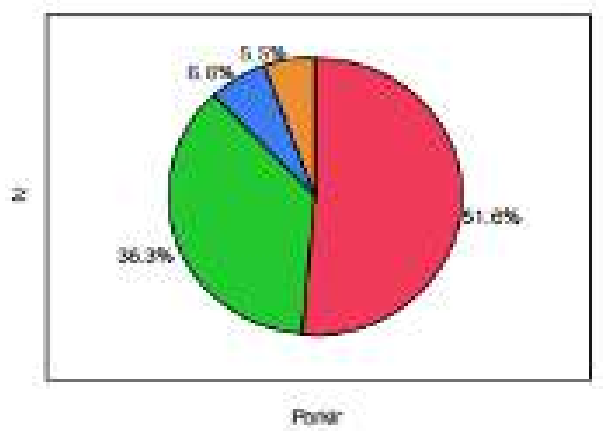

lowp bel.
Sorgut Bek

Gambar 3. Tingkat Kepuasan Pengunjung terhadap Kondisi Infrastruktur

\subsubsection{Kelancaran Jaringan Transportasi}

Berdasarkan hasil penelitian, dari 91 responden yang berkunjung ke Desa Wisata Taman Purbakala Pugungraharjo beranggapan bahwa kelancaran jaringan dilokasi desa wisata tersebut dianggap cukup lancar. Dimana skor parameter yang menunjukkan skor $40,7 \%$ pengunjung mengganggap jaringan transportasi menuju Desa Wisata ini cukup lancar.

\subsubsection{Keterjangkauan}

Faktor keterjangkauan dilihat dari lama jarak yang ditempuh dan ketersediaan angkutan umum. Sebagian besar responden (56\%) menempuh waktu selama lebih dari 120 menit untuk menuju desa wisata dari tempat tinggalnya. Sisanya kurang dari 120 menit. Dengan demikian, dapat disimpulkan bahwa pengunjung rata-rata berasal dari luar daerah (tempat tinggalnya jauh dari lokasi desa wisata).

Berdasarkan ketersediaan angkutan umum, sebagian besar responden $(35,2 \%)$ menyatakan bahwa angkutan umum dari dan menuju lokasi desa wisata cukup tersedia (ada namun agak sulit ditemukan). Sebagian lainnya yang menyatakan tersedia (mudah ditemukan) sebesar 28,6\%. Sebaliknya, 29,7\% menyatakan tidak tersedia (sangat sulit menemukan angkutan umum). Sisanya $4,4 \%$ merasa sangat mudah menemukan dan $2,2 \%$ sangat sulit menemukan angkutan umum. Dengan demikian, dapat disimpulkan bahwa ketersediaan angkutan umum cukup tersedia bagi sebagian besar pengunjung.
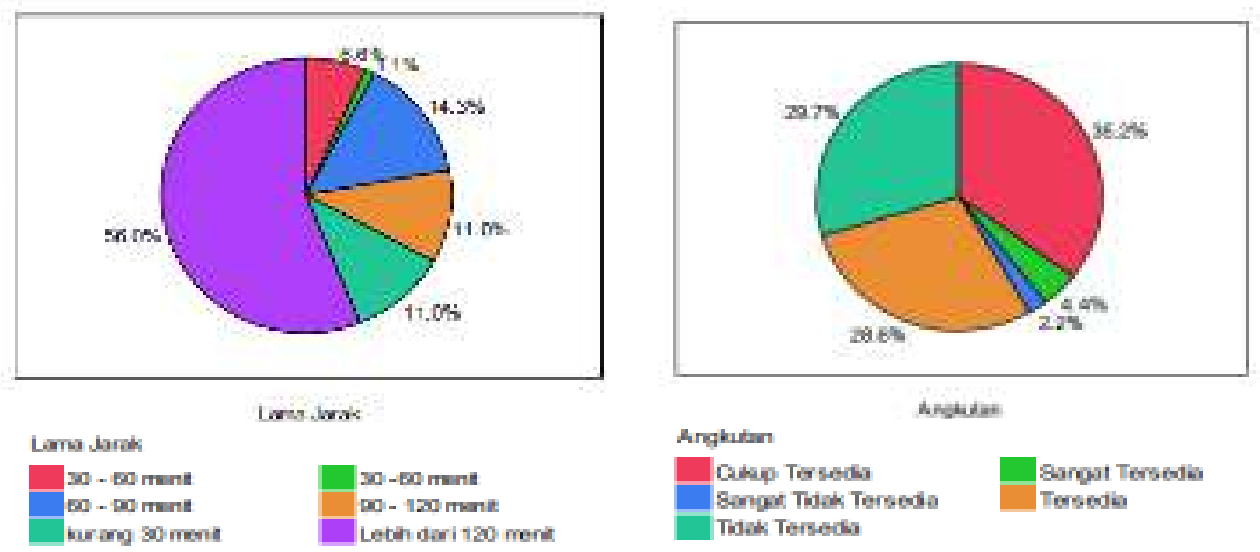

Gambar 4. Tingkat Kepuasan Pengunjung terhadap Keterjangkauan Desa Wisata

\subsubsection{Nilai Manfaat bagi Pengunjung}

Berdasarkan hasil penelitian, sebagian besar responden $(86,8 \%)$ yang datang menyatakan desa wisata ini memiliki manfaat. Nilai manfaat adanya Desa Wisata Taman Purbakala Pugungraharjo ini ialah sebagai edukasi sejarah untuk pelajar maupun mahasiswa, dan dapat mengenal peradaban manusia dari jaman prasejarah, jaman klasik (Hindu - Budha) maupun jaman Islam. 


\subsection{Tingkat Pengetahuan Pengunjung Terhadap Desa Wisata Taman Purbakala Pugungraharjo}

Untuk mengetahui tingkat pengetahuan pengunjung terhadap keberadaan Desa Wisata Taman Purbakala Pugungraharjo, maka sumber informasi yang didapatkan oleh pengunjung dapat menjadi faktor yang dapat dinilai. Maka ada dua faktor dalam tingkat pengetahuan pengunjung yang dapat dilihat, yaitu faktor pengetahuan pengunjung dan sumber informasi.

\subsubsection{Mengetahui Infomasi tentang Desa Wisata}

Sebagian besar responden $(79,1 \%$ ) yang berkunjung ke Desa Wisata Taman Purbakala Pugungraharjo sebagian besar pengunjung yang datang menyatakan pernah mengetahui desa wisata ini.

\subsubsection{Sumber Informasi Tentang Desa Wisata}

Sebagian besar responden $(42,9 \%)$ mengetahui sumber informasi Desa Wisata ini dari Keluarga/Teman . Sedangkan sebagian besar lainnya bersumber dari sosial media (39,6\%). Sisanya bersumber dari buku panduan wisata dan lain-lain. Dengan demikian, informasi tentang desa wisata ini terbagi menjadi dua media besar, yaitu media lisan (dari mulut ke mulut) dan media sosial (internet).

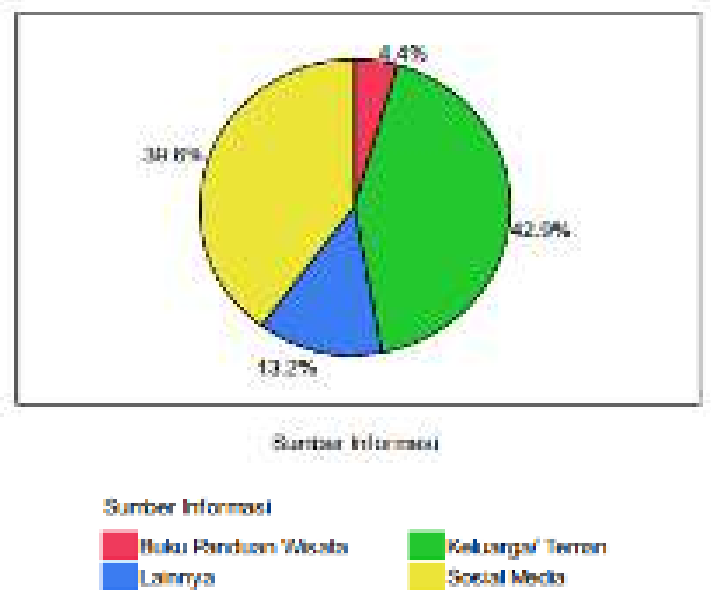

Gambar 5. Tingkat Pengetahuan Pengunjung terhadap Desa Wisata berdasarkan Sumber Informasinya

\section{Kesimpulan}

Dari hasil penelitian dan pembahasan, telah di proleh hasil dari tingkat kenyamanan, kepuasan dan pengetahuan pengunjung. Berdasarkan tingkat kenyamanan pengunjung, hasil penelitian menunjukkan bahwa pengunjung merasa cukup nyaman berada di Desa Wisata Taman Purbakala Pugungraharjo. Hal ini dibuktikan dari besarnya skor untuk masing-masing faktor kenyamanan, yaitu keindahan (46,2\% merasa tertarik), kebersihan $(53,8 \%$ menganggap bersih), aroma/bau-bauan (67\% mengangagap tidak bau), suara/kebisingan $(65,9 \%$ menganggap tidak bising, dan penghawaan (40,7\% menganggap biasa/normal atau tidak merasa kepanasan atau kedinginan).

Berdasarkan tingkat kepuasan pengunjung, hasil penelitian menunjukkan bahwa pengunjung merasa kondisi infrastruktur, area parkir, kelancaran jaringan transportasi, keterjangkauan lokasi, dan ketersediaan angkutan umum sudah cukup baik, meskipun sebagian lainnya mengangap masih perlu ada perbaikan. Secara lebih rinci, prosentase untuk kondisi infastruktur yaitu 39,6\% cukup baik dan kondisi area parkir 51,6\% pengunjung menganggap kondisinya baik. Sedangkan tingkat kepuasan pengunjung terhadap kelancaran jaringan transportasi menunjukkan skor $40,7 \%$ pengunjung menganggap cukup lancar. Dari faktor keterjangkauan lokasi cukup terjangkau, meskipun sebagian besar pengunjung (56\%) menempuh jarak lebih dari 120 menit dari tempat tinggal menuju lokasi. Ketersediaan angkutan umum menunjukkan skor 36,2\% pengunjung menganggap cukup tersedia. Sedangkan berdasarkan nilai manfaatnya, Desa Wisata Taman Purbakala Pugungraharjo ini masih dianggap bermanfaat oleh sebagian besar pengunjung dengan prosentase $86,8 \%$.

Berdasarkan tingkat pengetahuan pengunjung terhadap Desa Wisata Taman Purbakala Pugungraharjo, mayoritas pengunjung $(79,1 \%)$ menyatakan bahwa pernah mengetahui informasi tentang Desa Wisata ini. Sumber informasi sebagian besar $(42,9 \%)$ berasal dari kelurga/teman.

Dengan demikian dapat diketahui bahwa Desa Wisata Taman Purbakala Pugungraharjo ini masih cukup diminati oleh wisatawan, namun masih perlu banyak peningkatan dan perbaikan. Terutama dalam hal infrastrktur atau sarana prasarana yang disediakan. Untuk penelitian selanjutnya, perlu diketahui lebih dalam mengenai 
harapan masyarakat setempat dan pengunjung untuk pengembangan desa wisata ini. Sehingga hasil temuan dapat menjadi bahan pertimbangan pemerintah dan masyarakat dalam mengembangkan Desa Wisata Taman Purbakala Pugungraharjo sebagai desa wisata favorit sepanjang masa dan ramah terhadap lingkungan.

\section{Ucapan Terima Kasih}

Penulis menyampaikan ucapan terima kasih kepada Universitas Bandar Lampung atas dukungannya dalam mendorong civitas akademikanya dalam hal riset. Terima kasih juga kami sampaikan kepada pengelola Desa Wisata Taman Purbakala Pugungraharjo yang telah memberikan ijin melaksanakan penelitian dan mempermudah peneliti dalam proses pengumpulan data.

\section{Daftar Pustaka}

Creswell, J.W. (2008). Research Design: Qualitative, Quantitative, and Mixed Methods Approaches. California: Sage Publications, Inc.

Hakim, Rustam; Utomo, Hardi (2002). Komponen Perancangan Arsitektur Lansekap, Jakarta: Penerbit Bumi Aksara.

Mangunwijaya, Y.B. (1997). Pengantar Fisika Bangunan. Jakarta: Djambatan.

Notoatmodjo, S. (2007). Promosi Kesehatan dan Ilmu Perilaku. Jakarta: Rineka Cipta.

Zeithaml, Valarie A and Bitner. (2000). Service Marketing 2nd edition: Integrating Customer Focus. New York: McGraw-Hill Inc. 


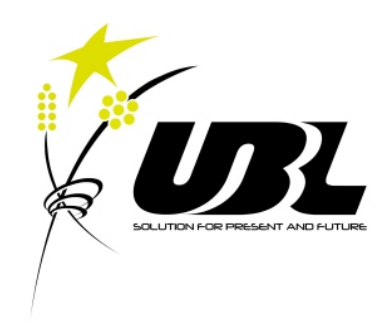

Published:

Program Studi Arsitektur Fakultas Teknik Universitas Bandar Lampung 